\title{
Knowledge of ASHA workers about maternal and child health services in Mysuru
}

\author{
Sugandha B.K. ${ }^{1}$, Jagannath P. ${ }^{2 *}$ \\ DOI: https://doi.org/10.17511/ijphr.2019.i4.06 \\ ${ }^{1}$ B K Sugandha, K S Hegde Medical Academy Nitte Deemed to be University, Mangalore, Karnataka, India. \\ 2* Jagannath $\mathrm{P}$, Head of the Department, Department of Public Health, K S Hegde Medical Academy Nitte Deemed to be University, \\ Mangalore, Karnataka, India.
}

\begin{abstract}
Background: Accredited Social Health Activist (ASHA) programme has been accepted, and the services utilization has been increased among many Indian communities since its inception in 2005 under National Rural Health Mission (NRHM). ASHA worker's knowledge is important for the success of this program. Objectives: To assess the level of knowledge of ASHA workers about Maternal and Child Health $(\mathrm{MCH})$ services. To determine the association between socio-demographic characteristics and the level of knowledge of ASHA workers about Maternal and Child Health services. Methods and Material: A cross sectional study was conducted among 295 ASHA workers of Mysuru Taluk, Karnataka from January to April 2019. Sample size was calculated based on the estimation of proportions method and all the ASHA workers were selected randomly. The semistructured self-administered questionnaire formulated based on the ASHA modules and translated into the local language (Kannada) was used for data collection. Descriptive data was analyzed by using frequency, percentage, mean and standard deviation. For the association between variables, Chi-square / Fisher's exact test was used. Results: Knowledge about Antenatal Care was average among half $(51.5 \%)$ of the participants. All the listed danger signs during pregnancy were identified only by $49.5 \%$ of ASHA workers. About $50 \%$ of the respondents were not aware of the exclusive breastfeeding till six months after birth. Conclusions: Knowledge levels about maternal and child health services were found to be average in most of ASHA workers.
\end{abstract}

Keywords: Accredited Social health Activist, Community Health Workers, Maternal and Child Health, National Health Mission, Knowledge

\section{Corresponding Author}

Jagannath $\mathrm{P}$, Head of the Department, Department of Public Health, K S Hegde Medical Academy Nitte Deemed to be University, Mangalore, Karnataka, India.

Email: jagannathp@nitte.edu.in
How to Cite this Article

To Browse

Sugandha BK, Jagannath P. Knowledge of ASHA workers about maternal and child health services in Mysuru. Public Health Rev Int J Public Health Res. 2019;6(4):169-176.

Available From

https://publichealth.medresearch.in/index.php/ijphr/ article/view/116

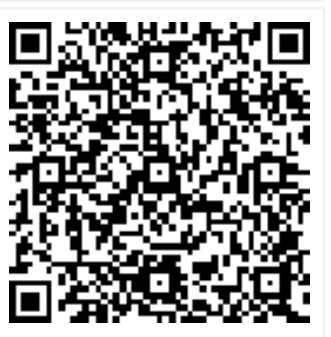

Manuscript Received 2019-08-08

Conflict of Interest No
Review Round 1 2019-08-18

Funding $\mathrm{Nil}$

Review Round 2
2019-08-24
Ethical Approval
Yes

Review Round 2

Yes
Review Round 3

Plagiarism X-checker $5 \%$
Accepted 2019-08-28

Note

(C) 2019 by B K Sugandha, Jagannath P and Published by Siddharth Health Research and Social Welfare Society. This is an Open Access article licensed under a Creative Commons Attribution 4.0 International License https://creativecommons.org/licenses/by/4.0/ unported [CC BY 4.0]. 


\section{Introduction}

Health is a fundamental human right all over the world and the main aspect to be considered for the growth of any society in social and economical terms, but sadly there exist an inequity in the provision of healthcare both in developing and developed world.

The perception of 'health for all' by Alma Ata declaration insists on decreasing these differences by stressing the importance of primary health care and strengthening the capacity of basic level health workers. With similar idea, in India the National Rural Health Mission (NRHM) (now National Health Mission (NHM)) was launched with the aim of addressing problems faced by the rural population in availing healthcare facilities [1].

One of the main factors that affect adversely on the healthcare delivery system in developing countries is the shortage of trained health workforce. Secondly, no health programs can be successful without community participation and acceptance. When looked for a solution to these problems, the concept of Community Health Workers (CHW) seems to be effective.

CHWs are appointed as basic level health workers who are from the community itself and can provide necessary services like mobilization, awareness about health and many more such services according to the need. This concept of CHW is time tested for more than 50 years in several countries and it has been found effective in improving the health outcomes of people especially in the field of Maternal and child health [2].

With this background, the Accredited Social Health Activist (ASHA) programme was launched as a key component of NRHM in 2005. ASHA plays the main role in bridging the gap between public health facilities and the communities by providing necessary and timely information about the healthrelated issues and available solutions. Ideally, ASHA should be staying in the same village where she works.

A married/ widowed/ divorced woman preferably in the age group of 25 to 45 years with minimum educational qualification being 10th standard is selected as an ASHA (relaxed in areas where ASHA workers are not available in adequate numbers fulfilling this criterion) through various community groups such as self-help groups, gram sabha and nodal officers.
ASHA being the first port of call to the deprived population are expected to facilitate community participation in public health programmes, especially among women and children. ASHA has to counsel pregnant women about Antenatal Care (ANC), birth preparedness and danger signs during pregnancy.

She has to provide information about the importance, duration, and frequency of breastfeeding to lactating mothers. Information about contraception and Reproductive Tract Infections (RTIs)/ Sexually Transmitted Diseases (STDs) has to be given to the eligible couple.

In most of the villages where the healthcare facilities are located far from the personal residence, they have to be dependent on ASHA for basic healthcare facilities like medicines for minor ailments, assistance in ANC, Intra Natal Care (INC) and Post Natal Care (PNC). After 12 years of the launch of ASHA services, now the community acceptance and utilization of ASHA services have increased [3]. ASHA's knowledge about these healthcare facilities will be critical in reducing the mortality and morbidity related to maternal and child health in any community.

ASHA being a link between the community and the health facilities should improve the community by providing health education and increasing service utilization. But studies have shown that the knowledge level of ASHA in most of the places was not complete that may lead ASHA to provide incorrect information to the community. Hence this study is conducted to assess the level of knowledge of ASHA workers about maternal health.

\section{Materials and Methods}

Study design: It is a community based crosssectional study

\section{Study setting: Mysuru Taluk, Karnataka}

Study duration: The study was conducted from January 2019 to April 2019. Data collection from all the PHCs of Mysuru Taluk was done during January and February 2019.

Study population: Trained ASHA workers in Mysuru Taluk, who had experience of at least 1 year were the study participants.

Sample size: A study conducted in Udupi Taluk in 2017 has revealed that the knowledge among ASHA workers about ANC and PNC as $82 \%$. That is taken as the prevalence of knowledge. 
To calculate sample size, technique of estimation of proportion is used

$$
\begin{aligned}
& n=\frac{\left(z_{1-\alpha / 2}\right)^{2}(p)(1-p)}{d^{2}} \\
& n=\frac{(1.96)^{2}(0.82)(1-0.82)}{(0.05)^{2}} \\
& n=\frac{(3.8416)(0.1476)}{0.0025}
\end{aligned}
$$

$-\mathrm{n}=226.80 \approx 227$

Adding non response rate of $30 \%=227+68=295$

Where,

(Z1-a/2)- For $95 \%$ Confidence Interval is 1.96

P - Prevalence of knowledge i.e., 82\% (0.82)

$\mathrm{Q}-(1-\mathrm{p})=0.18$

D - Level of precision i.e., 5\% (0.05)

$\mathrm{N}$ - Sample size $=295$

2.6 Sampling technique: Two-stage sampling method was adopted. The list of ASHA workers functioning in Mysuru Taluk with their respective PHCs was obtained. In the first stage the 34 PHCs of the Mysuru Taluk were divided into rural and urban. In the second stage based on the calculated sample size, proportion allocation of number of ASHAs was done for both rural and urban PHCs. All the ASHA workers ID numbers were entered in Microsoft excel and selection of ASHA workers was done based on random sampling method.

Inclusion criteria: ASHA workers trained in all modules based on the NHM guidelines.

Exclusion criteria: Eligible participants not willing to consent

Study tool: Self-administered (semi-structured) questionnaire was used to collect the information. The questionnaire was framed based on the training modules for ASHA provided by NHM. The classification of knowledge was done based on the percentiles. Below the score of 25th percentile i.e., less than or equal to 29 was considered as poor. 30 to 35 was considered as average and 36 and above as good (above 75th percentile). The questionnaire was developed in English and then translated into the Kannada language.
Validity of the tool: The questionnaire was validated by a pilot study conducted on 29 ASHA workers of Mysuru Taluk. Necessary changes were made and the tool was finalized for the study. Cronbach's alpha was 0.76 .

Procedure of data collection: Data collection was carried out by the researcher through self administered questionnaire. All the Medical Officers (MO) of PHCs in Mysuru Taluk were contacted and obtained permission for data collection during their monthly meetings with ASHA workers or any other possible days when ASHAs can gather.

On prescribed dates ASHAs of respective PHCs were administered with the questionnaire. Details about the researcher, purpose and nature of study was explained. Information about voluntary participation was given. Written consent was taken from all the participants.

Data analysis: The collected data was entered and edited in SPSS version 16.0. Descriptive data was analyzed by using frequency, percentage, mean and standard deviation. For the association between variables, Chi-square / Fisher's exact test was used. $P$ value less than 0.05 was considered as statistically significant.

Ethical considerations: Ethical clearance was obtained from Institutional Ethics Committee, $\mathrm{K} \mathrm{S}$ Hegde Medical Academy, Nitte (Deemed to be University) (\#INST. EC/EC/136/2018-19). To conduct the study, permission was obtained from the Director, Health and Family Welfare services, Bengaluru.

Participants were explained about the objectives and the nature of the study. Informed consent was taken from each participant before administering the questionnaire. Identity of the participants was anonymized.

\section{Results}

Socio-Demographic characteristics: The number of ASHA workers participated in the study was 295. Out of that $51.9 \%$ of them belonged to the age group of 25 to 34 years. The age of participants ranged from 21 years to 53 years, mean age being 34.35 with Standard Deviation (S.D) 5.95 years. More than half of the participants (61.3\%) were educated up to 8 th to 10 th standard. Among the participants, $86.4 \%$ were married, $11.2 \%$ were widowed and $0.7 \%$ of them were un-married. 
Around $44 \%$ of the ASHA workers cover the population of 1001 to 2000 followed by $38.2 \%$ served population below 1000 (Table 1).

Table-1: Socio - demographic characteristics of the respondents

\begin{tabular}{|c|c|c|}
\hline Characteristics $(n=295)$ & Frequency & Percentage \\
\hline \multicolumn{3}{|l|}{ Age (in years) } \\
\hline Below 24 & 6 & 2.0 \\
\hline 25 to 34 & 153 & 51.9 \\
\hline 35 to 44 & 118 & 40.0 \\
\hline Above 44 & 18 & 6.1 \\
\hline \multicolumn{3}{|l|}{ Education } \\
\hline Primary & 40 & 13.6 \\
\hline Secondary & 181 & 61.3 \\
\hline Pre - University & 66 & 22.4 \\
\hline Graduate/ Diploma & 8 & 2.7 \\
\hline \multicolumn{3}{|l|}{ Marital status } \\
\hline Divorced & 5 & 1.7 \\
\hline Married & 255 & 86.4 \\
\hline Un-married & 2 & 0.7 \\
\hline Widowed & 33 & 11.2 \\
\hline \multicolumn{3}{|l|}{ Family type } \\
\hline Joint & 74 & 25.1 \\
\hline Nuclear & 221 & 74.9 \\
\hline
\end{tabular}

Table-1 (Continued): Socio - demographic characteristics of the respondents

\begin{tabular}{|c|c|c|}
\hline Characteristics $(n=295)$ & Frequency & Percentage \\
\hline \multicolumn{3}{|l|}{ Place of residence } \\
\hline In the headquarter & 270 & 91.5 \\
\hline Out of the headquarter & 25 & 8.5 \\
\hline \multicolumn{3}{|l|}{ Allotted population } \\
\hline Below 1000 & 113 & 38.2 \\
\hline 1000 to 2000 & 130 & 44.1 \\
\hline 2000 to 3000 & 40 & 13.6 \\
\hline 3000 to 4000 & 9 & 3.1 \\
\hline More than 4000 & 3 & 1.0 \\
\hline \multicolumn{3}{|l|}{ Years of experience } \\
\hline 1 to 3 & 161 & 54.5 \\
\hline 4 to 6 & 5 & 1.7 \\
\hline 7 to 9 & 108 & 36.6 \\
\hline Above 9 & 21 & 7.2 \\
\hline
\end{tabular}

Knowledge of the respondents about Maternal and Child Health: Knowledge of $90.5 \%$ of the respondents about birth spacing and contraception was found to be good. About half of the respondents $(51.5 \%)$ had average knowledge about the Antenatal Care (ANC) whereas $86.1 \%$ of them had good knowledge about Post Natal Care (PNC). About $78 \%$ of the respondents knew about the advice given for birth preparedness (Table 2).
Table-2: Knowledge of the respondents about Maternal and Child Health

\begin{tabular}{|l|l|l|l|}
\hline Characteristics $(\mathrm{n}=\mathbf{2 9 5})$ & Poor $\mathbf{n}(\%)$ & Average $\mathbf{n}(\%)$ & Good $\mathbf{n}(\%)$ \\
\hline Pregnancy testing kit & $2(0.7)$ & $107(36.2)$ & $186(63.1)$ \\
\hline Antenatal care & $4(1.3)$ & $152(51.5)$ & $139(47.2)$ \\
\hline Danger signs during pregnancy & $76(25.7)$ & $24(8.2)$ & $195(66.1)$ \\
\hline Birth preparedness & $3(1)$ & $63(21.4)$ & $229(77.6)$ \\
\hline Post Natal Care & $7(2.4)$ & $34(11.5)$ & $254(86.1)$ \\
\hline Breastfeeding & $1(0.3)$ & $76(25.7)$ & $218(73.9)$ \\
\hline Birth spacing and & $5(1.7)$ & $23(7.8)$ & $267(90.5)$ \\
\hline contraception & & & $230(78)$ \\
\hline Immunization & $4(1.4)$ & $61(20.6)$ & \\
\hline
\end{tabular}

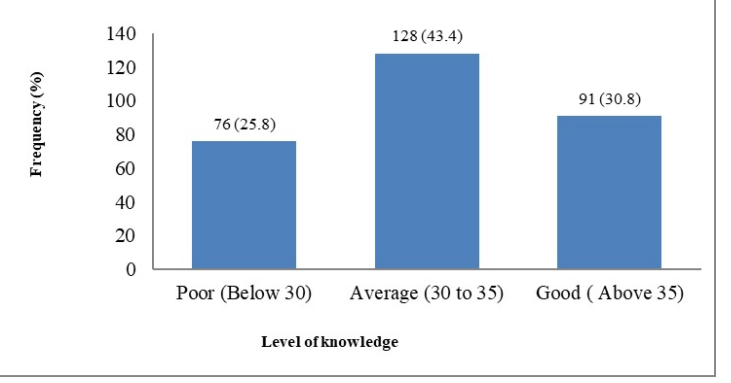

Figure-1: Classification of participants based on knowledge score

Knowledge about ANC: Need for early identification of pregnancy was correctly identified by $76.3 \%$ of the respondents. Minimum number of ANC visits was answered correctly as 4 by $98 \%$ but almost $30 \%$ of them could not answer correctly about the ANC visit schedule.

About $60 \%$ of the respondents could identify all the laboratory investigations done during ANC visits. Number of $\Pi T$ injections to be given to pregnant women during first pregnancy was known to $95.6 \%$ of the respondents. Ideal weight gain during pregnancy per month was correctly known by only $34.2 \%$ of the participants.

Knowledge about PNC: There was correct knowledge about cord care among $97.6 \%$ and $90.8 \%$ of them correctly identified the scheduled days an ASHA should visit recently delivered mother. Only $30.2 \%$ of the respondents could answer correctly about the weight to be considered as Low Birth Weight (LBW) soon after birth. Advising about kangaroo mother care was known to be given to LBW baby by $95.3 \%$.

Knowledge about Breastfeeding: Time of initiation of breastfeeding was correctly known by $96.9 \%$ of the respondents. 
Most of the respondents $(99.7 \%)$ answered that pre-lacteal feeds should not be given to baby and $98 \%$ of the respondents correctly responded that colostrum should be fed to baby without discarding initially. About exclusive breastfeeding, $49.2 \%$ of them responded water, milk formula or cow's milk can be given to baby till 6 months after delivery.

Knowledge about Immunization: The immunization to be given to the baby on first day of birth was correctly identified as BCG by $95.3 \%$ of the participants. As per the immunization schedule vaccination against measles to be given was asked. Among the participants of the study $81.4 \%$ of them could identify it as in 9th month of baby.

Classification of participants based on knowledge score- The classification was done based on the percentiles. Below the score of 25th percentile was considered as poor that is less than or equal to 29 was considered as poor. 30 to 35 was considered as average and 36 and above as good (above 75th percentile). Among the ASHA workers, $30.8 \%$ and $43.4 \%$ of them had good and average knowledge respectively. (Figure 1)

Association of knowledge with sociodemographic characteristics- Knowledge was found to be having statistically significant association with level of education of ASHA workers, population covered by each ASHA worker and the time spent on house visits in a week with the $p$ value $>0.05$. (Table 3 )

Table-3: Association of Knowledge with sociodemographic factors.

\begin{tabular}{|c|c|c|c|c|}
\hline Variables & $\begin{array}{l}\text { Poor (Below } \\
\text { 30) }(\%)\end{array}$ & $\begin{array}{l}\text { Average (30 to } \\
35)(\%)\end{array}$ & $\begin{array}{c}\text { Good (Above } \\
35)(\%)\end{array}$ & $\begin{array}{c}P \\
\text { value }\end{array}$ \\
\hline \multicolumn{5}{|l|}{ Education } \\
\hline Primary & $12(15.8)$ & $17(13.3)$ & $11(12.1)$ & \multirow{4}{*}{$\begin{array}{l}<0.00 \\
1 * *\end{array}$} \\
\hline Secondary & 58 (76.3) & $76(59.4)$ & 47 (51.6) & \\
\hline $\begin{array}{l}\text { Pre- } \\
\text { University }\end{array}$ & $4(5.3)$ & $31(24.2)$ & 31 (34.1) & \\
\hline $\begin{array}{l}\text { Graduate/ } \\
\text { Diploma }\end{array}$ & $2(2.6)$ & $4(3.1)$ & $2(2.2)$ & \\
\hline \multicolumn{4}{|l|}{ Family type } & \multirow[t]{3}{*}{0.94} \\
\hline Joint & $20(26.3)$ & $31(24.2)$ & $23(35.3)$ & \\
\hline Nuclear & 56 (73.7) & $97(75.8)$ & $68(74.7)$ & \\
\hline \multicolumn{5}{|c|}{ Allotted population } \\
\hline Below 1000 & $38(50)$ & 49 (38.3) & $26(28.6)$ & \multirow[t]{4}{*}{$0.02 *$} \\
\hline 1001 to 2000 & $26(34.2)$ & $56(43.8)$ & 48 (52.7) & \\
\hline 2001 to 3000 & $7(9.2)$ & $20(15.6)$ & $13(14.3)$ & \\
\hline 3001 to 4000 & $5(6.6)$ & $1(0.8)$ & $3(3.3)$ & \\
\hline
\end{tabular}

\begin{tabular}{|l|l|l|l|l|}
\hline More than 4000 & $0(0)$ & $2(1.6)$ & $1(1.1)$ & \\
\hline \multicolumn{3}{|l|}{ Time spent in household visits in a week (in hours) } \\
\cline { 1 - 4 } Below 15 & $10(13.2)$ & $7(5.5)$ & $1(1.1)$ & \multirow{2}{*}{$0.028^{*}$} \\
\cline { 1 - 4 } 16 to 30 & $61(80.3)$ & $113(88.3)$ & $85(93.4)$ & \\
\hline 31 to 45 & $5(6.6)$ & $8(6.2)$ & $5(5.5)$ & \\
\hline
\end{tabular}

$*$ p value $<0.05$

**p value $<0.01$

\section{Discussion}

In the present study it was found that about half of the respondents ( $51.9 \%$ ) were aged 25 to 34 years. Similar findings were obtained in a study conducted by Desai et al. in which around $71 \%$ of the ASHA workers were aged between 25 to 34 years [4]. ASHA workers are involved in mobilizing the community, the age group is an important factor since it requires physical strength. Hence the ideal age group recommended by NHM is 25 to 45 years. This study found that more than $90 \%$ of the ASHA workers belonged to this age group. In this study, $61.4 \%$ of the study participants were educated up to High school, and $13.6 \%$ were educated up to 7 th standard. These findings are similar to the study conducted by Nagaraj et al. where $77.3 \%$ were educated up to high school and $9.7 \%$ up to middle school [5].

About $83 \%$ of the ASHA workers covered the population up to 2000 and the rest of them covered the population of more than 2000 similar results was found in the study conducted by Bhandari et al. that is $73.75 \%$ of them were covering the population of 1000 to 1500 , and $5 \%$ of them were covering the population of more than 1500 [6]. Even though the maximum population to be covered by each ASHA is 1000, due to lack of availability of human resources they have been allotted more than the ideal number of populations.

In the present study it is found that only $47.2 \%$ of the respondents have good knowledge about ANC. A study conducted by Kori et al. found that $12.5 \%$ and $14.7 \%$ of the respondents had very good and good knowledge about ANC respectively [7]. The minimum number of ANC visits was correctly identified as four by $98 \%$ of the respondents, but the recommended schedules of these visits were known only by $70.8 \%$. The number of $T$ injections to be given in the first pregnancy and number of IFA tablets to be taken was also known correctly by $96.6 \%$ and $79.7 \%$ respectively. But only $24.4 \%$ of the respondents could identify all the three listed side effects of IFA tablets. 
Similarly, the study conducted by Shashank et al. found that $79.5 \%$ of the respondents answered that there should be minimum four compulsory ANC visits and $90 \%$ and $100 \%$ of the ASHA workers agree that Iron and calcium tablets should be provided to pregnant women and $\pi$ injection has to be given respectively [8].

All the four danger signs during pregnancy enlisted in the questionnaire were identified by only $49.5 \%$ of the participants. A study conducted by Kohli et al. found that $85.5 \%$ of the ASHA workers participated in the study said that pregnant women with vaginal bleeding should be referred. In case of loss of fetal movements and swelling of feet 76.4 and $54.5 \%$ of them advise referral [9].

Since in time referral of pregnant women in case of complications can save their lives and helps in taking the precautions while conducting delivery, identification of such symptoms as early as possible is important, but in the present study, less than half of the participants could identify all the danger signs.

Only $67.5 \%$ of the ASHAs could identify all the four enlisted elements of birth preparedness. According to the study conducted by Grover et al., more than $80 \%$ of the ASHAs reported that they counsel for all the elements of birth preparedness [10]. Counseling about the birth preparedness and helping pregnant women to decide about all those elements is a major responsibility of ASHA but knowledge about the same was not found to be satisfactory in this study.

Knowledge about breastfeeding was very good except for the exclusive breastfeeding. Only half of them $(50.8 \%)$ responded there should be exclusive breastfeeding till six months after birth. In a study conducted by Saxena et al. they found that only $23 \%$ of them knew about exclusive breastfeeding until six months after delivery [11].

Only about $30 \%$ of the respondents could identify the weight of LBW baby as less than $2.5 \mathrm{kgs}$, but $93.2 \%$ knew that LBW baby couldn't be bathed before seven days of birth. About Kangaroo Mother Care $95.3 \%$ of the ASHA workers knew that it is advised for LBW babies. A study conducted by Bansal et al. found that the knowledge of ASHA workers about encouraging Kangaroo mother Care was $68 \%$ [12]. Identification of LBW babies and advising proper care can promote effective homebased care in the areas where the availability of healthcare facilities is less.
In this study knowledge about immunization was found to be good among $78 \%$ of the study participants. According to the study conducted by Kori et al. in 2015 more than $60 \%$ of the respondents had good knowledge about the immunization [7]. Good knowledge about the immunization schedule is important for ASHA workers to guide the community to get timely immunization services. The minimum spacing between two children was correctly answered as three years by $93.9 \%$ of the respondents, and $94.9 \%$ could correctly identify the spacing method among other permanent contraceptive methods. The study conducted by Ratnam et al. found that $100 \%$ of the ASHA workers knew the permanent and spacing methods of contraception provided by the government [13]. The knowledge about the types of contraceptive methods is important to be known by ASHA workers since it helps them to counsel the couple based on whether the family size is complete or not.

\section{Limitations}

Since it is a cross sectional study, enhancement or declination in knowledge over time could not be studied. The knowledge level is studied only on a selected district, so generalization was not possible.

\section{Conclusion}

The level of knowledge was average among almost half of the participants. Community mobilization is an important responsibility of ASHA workers especially for ANC visits of pregnant women. But the knowledge about the schedule for the same was lacking among one third of the respondents. In spite of being trained regularly and more than one-third of them having field experience of more than six years, few ASHAs were still recommending prelacteal feeds, and most of them are not aware of the concept of exclusive breastfeeding till six months after birth. The knowledge about important elements like identification of the danger signs in pregnancy and birth preparedness plan were incomplete.

\section{What this study adds to existing knowledge}

In the aspects such as knowledge about pregnancy testing kit, ANC, PNC, immunization, and family planning most of their knowledge was found to be good, but the detailed knowledge about all these 
Aspects lacked in many ASHA workers. By this it can be concluded that even though majority of the ASHA workers knew their responsibilities and had knowledge about the services to be provided the rationale and main idea behind these were not very well understood.

\section{Author's contributions}

Both the author contributed equally in the concepts, design, definition of intellectual content, literature search, data acquisition, data analysis, statistical analysis, manuscript preparation.

\section{Reference}

01. Declaration of Alma-Ata [Internet]. Alma-Ata, USSR. 1978 Sep [cited 2019 Mar 18].

Available at: [Article] [Crossref]

02. Lehmann U, Sanders D. Community health workers- what do we know about them, The state of the evidence on programmes, activities, costs and impact on health outcomes of using community health workers. Geneva- World Health Organization. 2007;1-42.

[Crossref]

03. Ministry of Health and Family Welfare. About ASHA [Internet]. National Health Mission. 2014 Sep [cited 2018 Aug 23].

Available from: in/ communitisation/asha/aboutasha.html [Article] [Crossref]

04. Desai PB. Role of Accredited Social Health Activists (ASHAS) in the Improvement of Health Status of Villagers under NRHM in Kolhapur District, Maharashtra. J Com Med Health Edu. 2016;6(2)1-12.

doi: 10.4172/2161-0711.1000416 [Crossref]

05. Nagaraj S, Achapppa S, Bettapa P. Performance Evaluation of Accredited Social Health Activist under National Rural Health Mission in Mysore District: A Cross-Sectional Study. Natl J Community Med. 2017; 8 (6): 324-328.

[Crossref]

06. Bhanderi DJ, Varun AR, Sharma DB. Evaluation of accredited social health activists in Anand District of Gujarat. J Fam Med Prim care. $2018 ; 7(3) 571-576$.

doi: 10.4103/jfmpc.jfmpc_207_17 [Crossref]
07. Kori S, Bhatia M, Mishra A. A Cross-sectional Assessment of Knowledge of ASHA Workers. Journal of Krishna Inst Med Sci (JKIMSU). 2015;4(4)57-63.

[Crossref]

08. Shashank Kj, Angadi M. A study to evaluate the knowledge of ASHA workers on antenatal and postnatal care in Bijapur district. Int J Res Med Sci. 2015;3(9)2299-2302. doi: [Article] [Crossref]

09. Kohli C, Kishore J, Sharma S, Nayak H. Knowledge and practice of Accredited Social Health Activists for maternal healthcare delivery in Delhi. J Family Med Prim Care. 2015;4(3)359363.

doi: 10.4103/2249-4863. 161317 [Crossref]

10. Grover K, Khanna P, Kumar R, Verma R. Birth Preparedness and Knowledge of ASHAs regarding danger signs of pregnancy in rural India- A cross sectional study. Int J Res Dev Pharm L Sci. 2017;6(7)2850-2855.

doi: $\quad 10.21276 /$ IJRDPL.2278-0238.2017.6(7).28502855 [Crossref]

11. Saxena S, Singh AK, Maheshwari S, Gupta SB. Appraisal of knowledge of ASHA regarding child health services provided under NHM in Bhojipura block, District Bareilly. Int J Comm Med Public Health. 2017;4(10)3705-3711. doi: 2394-6040.ijcmph20174237 [Article] [Crossref]

12. Bansal SC, Nimbalkar SM, Shah NA, Shrivastav RS, Phatak AG. Evaluation of knowledge and skills of home based newborn care among Accredited Social Health Activists (ASHA). Indian Pediat. 2016;53(8)689-691.

[Crossref]

13. Ratnam AL, Kumaran JA. Awareness of family planning services among ASHA workers in a municipality of northern Kerala. Int J Comm Med Public Health. 2018;5(8)3413-3417.

doi: $\quad$ 10.18203/2394-6040.ijcmph20183072 [Crossref] 